\title{
Standard precautions: knowledge and practice among nursing and medical students in a teaching hospital in Brazil
}

\author{
Mary Rocha-Carneiro García-Zapata ${ }^{{ }^{*}}$, Adenícia Custódia Silva e Souza ${ }^{2}$, Janaína Valadares Guimarães ${ }^{2}$, \\ Anaclara Ferreira Veiga Tipple 2 , Marinésia Aparecida Prado ${ }^{2}$, Marco Tulio Antonio García-Zapata ${ }^{1,3}$ \\ ${ }^{1}$ Teaching Hospital, Federal University of Goias, Goiania, Brazil \\ ${ }^{2}$ School of Nursing, Federal University of Goias, Goiania, Brazil \\ ${ }^{3}$ Institute of Tropical Pathology and Public Health, Federal University of Goias, Goiania, Brazil
}

doi: 10.3396/ijic.V6i1.005.10

\begin{abstract}
Compliance with standard precautions measures is essential to prevent and control healthcare-associated infections. The objective of the study was to evaluate the knowledge and practice of hand washing, use of gloves and the handling and disposal of needlesticks and other sharp objects among nursing and medical students. This is a descriptive observational study, which used a questionnaire and a check list. Knowledge of standard precaution measures was evaluated in 48/48 (100.0\%) nursing students and 93/112 (83.0\%) medical students. At the teaching hospital, 26/37 (70.3\%) nursing students and 78/93 (83.9\%) medical students belonging to the population being investigated were observed during their clinical practice. These results were compared intra groups. Knowledge of hand hygiene procedures was higher than what was observed in the clinical practice in both groups of students, $\left(\chi^{2} ; p \leq 0.001\right)$. Compliance with the use of sterile and non-sterile gloves, and handling and disposal of needlesticks and other sharp objects was higher than the knowledge of these procedures among nursing students, and a statistically significant difference was observed with regards to sterile glove usage $\left(\chi^{2} ; p=0.009\right)$. Regarding medical students, there was no statistical difference between knowledge and practice insofar as these two types of gloves were concerned, as well as regarding the handling and disposal of needlesticks and other sharp objects. Performance of both groups in terms of knowledge of hand hygiene showed a dichotomy between the teaching and the practice of these standard precautions. Results have shown a deficiency in the teaching-learning process for the other measures evaluated.
\end{abstract}

\section{Keywords}

Health Knowledge, Attitudes, Practice; Nursing students; Medical students; Universal precautions; Teaching Hospital.

\section{Corresponding author}

Mary Rocha-Carneiro Garcia-Zapata, Nosocomial Infection Control Commission, Teaching Hospital,

Federal University of Goias, Goiania, Brazil, Address: Caixa Postal 12911 - Setor Leste Vila Nova, CEP 74643-970

- Goiania-GO, BRAZIL, Tel: 5562 3269-8209, Fax: 5562 3269-8219; 5562 3521-1839,

Email: maryrocar@yahoo.com.br 


\section{Introduction}

Compliance on the part of Healthcare workers (HCWs) including nursing and medical students with standard precautions has been recognized as being an efficient means to prevent and control healthcare-associated infections. Such measures not only protect the patient, but also the HCWs and the environment. ${ }^{1,2}$ Among the standard precautions advocated, hand hygiene is considered, in itself, the most important one. ${ }^{3,4}$ Another important measure is the adequate use of gloves, whose purpose is to protect the HCWs, as well as the patient. A preventive measure also worthy of mention is the adoption of safe practices for handling needlesticks and other sharp objects, in view of the possibility of outbreaks, especially of Hepatitis B and C, frequently associated to the offer of healthcare. ${ }^{2}$ However, in spite of the effectiveness of these standard precautions, what reality shows us is very low compliance with these measures, by professionals and students alike.

When entering university, a student pursuing a degree in health sciences is not required to have fulfilled any prerequisites in the area, therefore, his or her undergraduate years are the appropriate moment for acquiring the necessary knowledge and skills. ${ }^{5}$ However, only very few disciplines approach this area of study and provide knowledge on the standard procedures to students who, after graduation, would be theoretically prepared to enter the job market. For this purpose, the authors developed this study, to evaluate both the knowledge and the practice of standard precautions by nursing and medical students in the teaching hospital of a public university in the State of Goiás, Brazil.

\section{Methods}

Descriptive observational study, on a population comprised of last-year students enrolled in the Nursing $(n=48)$ and Medical $(n=112)$ schools of a public university in Goias, Brazil.

The study was developed in two moments: during this first moment, knowledge on standard precautions (SP) was evaluated by means of a questionnaire. During the second moment, a check list was used to record practical activities performed by the students while serving their internship.
Ethical aspects of the study were considered and those who agreed to participate in this study were asked to sign an informed consent (IC).

\section{Instruments used for data collection}

Both the questionnaire and the check list were drafted in a structured format and they were used in a pilot test before being applied to the students enrolled in this study. The questionnaire was drafted according to Garner's ${ }^{1}$ recommendations and included questions about the students' knowledge of: Hand hygiene (indication, areas deserving particular attention, and minimum time for the procedure); sterile and nonsterile gloves (indication); needlesticks and other sharp objects (handling and disposal).

Degree of knowledge was ascertained by means of yes-no questions on each item being evaluated.

The students were asked to answer the questionnaire in the course of their normal classroom activities. Both the questionnaire and the IC form had a corresponding identification number, thus allowing the authors to pair them and compare answers with observed practice.

Practical observation was done for those students who had answered the questionnaire and had served their apprenticeship at the school hospital. Passive, nonparticipative observation, was performed during a sixmonth period, while students were doing their clinical practice. Data were collected by 10 research assistants, who had been given orientation and qualification courses. The parameters observed and recorded on the check list corresponded to the practice of aspects that had been evaluated during the knowledge assessment phase.

\section{Data Analysis}

Collected data were statistically processed with Sigma Stat ${ }^{\circledR}$ software, version 2.03. The Kolmogorov-Smirnov test was used with the variables to determine data normality and the non-parametric Mann-Whitney test was used to compare the two groups. The chi-square $\left(\chi^{2}\right)$ or the Fisher Exact Test were used to compare proportions. Differences smaller than 5\% $(p<0.05)$ were considered statistically significant. 
Correct answers to the items that comprised each topic being evaluated were the criteria used to measure the student's knowledge of standard precautions. Compliance with standard precaution measures during clinical practice was noted as such, only when the students complied in all the required instances. For the statistical analysis of each SP evaluated, students who did not answer the corresponding item in the questionnaire or those which were not observed during clinical practice were not considered.

The difference between knowledge and practice among the students was evaluated among those pursing the same degree program (intra course evaluation).

\section{Results}

Forty-eight (100.0\%) nursing students and 93 (83.0\%) medical students answered the questionnaire. Twentysix $(70.3 \%)$ nursing students and 78 (83.9\%) medical students from the estimated population were observed during clinical practice. One of the nursing students was evaluated only in regarding to indication for hand hygiene. There was no significant statistical difference between the estimated population and the population observed during clinical practice, as per the Mann Whitney test; $p=0.333$.
Fifty-eight procedures performed by 26 nursing students and 164 procedures performed by 78 medical students were observed, for a total of 222 procedures with an indication for hand hygiene $(\mathrm{HH})$, before and after each procedure, which meant 444 opportunities to clean the hands.

Among the 58 procedures observed/performed by the nursing students, 26 (44.8\%) and 18 (31.0\%) had an indication for sterile and non-sterile gloves usage, respectively. The 14 remaining procedures required only washing the hands.

All the 164 procedures performed by the medical students had an indication for hand hygiene. Among these procedures, 45 (27.4\%) also indicated the use of non-sterile gloves and four (2.4\%) required sterile gloves. It was determined that $115(70.1 \%)$ procedures observed/performed by the medical students were physical check ups on patients that did not involve evaluation of the mucosa and/or the possibility of contact with body fluids. They only required the hands to be washed before and after the procedures were performed.

Table I: Difference between knowledge and practice regarding the indications for hand hygiene among nursing and medical students in a teaching hospital

\begin{tabular}{|c|c|c|c|c|}
\hline Students & Indications of Hand Hygiene & $\begin{array}{l}\text { Knowledge } \\
\text { n (\%) }\end{array}$ & $\begin{array}{l}\text { Practice } \\
\text { n (\%) }\end{array}$ & p \\
\hline \multirow[t]{4}{*}{ Nursing $(n=26)$} & Only before patient care & $0(0.0)$ & $1(3.8)$ & $p=1.000$ \\
\hline & Only after patient care & $0(0.0)$ & $6(23.1)$ & $p=0.023$ \\
\hline & Before and after patient care & $26(100.0)$ & $7(26.9)$ & $p \leq 0.001$ \\
\hline & $\begin{array}{l}\text { Neither before } \\
\text { nor after patient care }\end{array}$ & $0(0.0)$ & $12(46.2)$ & $p \leq 0.001$ \\
\hline \multirow[t]{4}{*}{ Medical $(n=78)$} & Only before patient care & $4(5.1)$ & $0(0.0)$ & $p=0.129$ \\
\hline & Only after patient care & $2(2.6)$ & $11(14.1)$ & $p=0.020$ \\
\hline & Before and after patient care & $71(91.0)$ & $2(2.6)$ & $p \leq 0.001$ \\
\hline & $\begin{array}{l}\text { Neither before } \\
\text { nor after patient care }\end{array}$ & $1(1.3)$ & $65(83.3)$ & $p=0.001$ \\
\hline
\end{tabular}




\section{Hand Hygiene}

The Table I shows the profile of the knowledge and practice among nursing and medical students in regarding to the indications for hand hygiene. The study ascertained that $100 \%$ of the nursing student and $91 \%$ of the medical students knew that their hands had to be washed before and after patient care. However, compliance with $\mathrm{HH}$ was noted in $26.9 \%$ of the nursing students and $2.6 \%$ of the medical students. Twelve nursing students (46.2\%) and 65 (83.3\%) of the medical students did not wash their hands before or after caring for their patients (Table I). There was a statistical difference between knowledge and practice in all indications of hand hygiene for both students groups, except, in the indication: "just before of the patient care" (Nursing students: Fisher Exact Test; Medical students: $\chi^{2}=2.309$ ).
It was also possible to ascertain that in only one occasion did nursing students wash their hands for the required period of time and with the recommended care. In no occasion did medical students wash their hands according to the acceptable practices

\section{Use of sterile and non-sterile gloves}

The Figure 1 reveals the knowledge and the practice of the use of sterile and non-sterile gloves between both groups of students. In the brief comparison of these standard precautions was verified that the performance nursing students was superior to the medical students. Regarding of using sterile gloves, there was statistical difference only in the nursing students $\left(\chi^{2}=6.839\right.$; $\mathrm{p}=0.009$ ). In these, the practice among those who wore gloves adequately was superior to their knowledge on the matter (Figure 1).

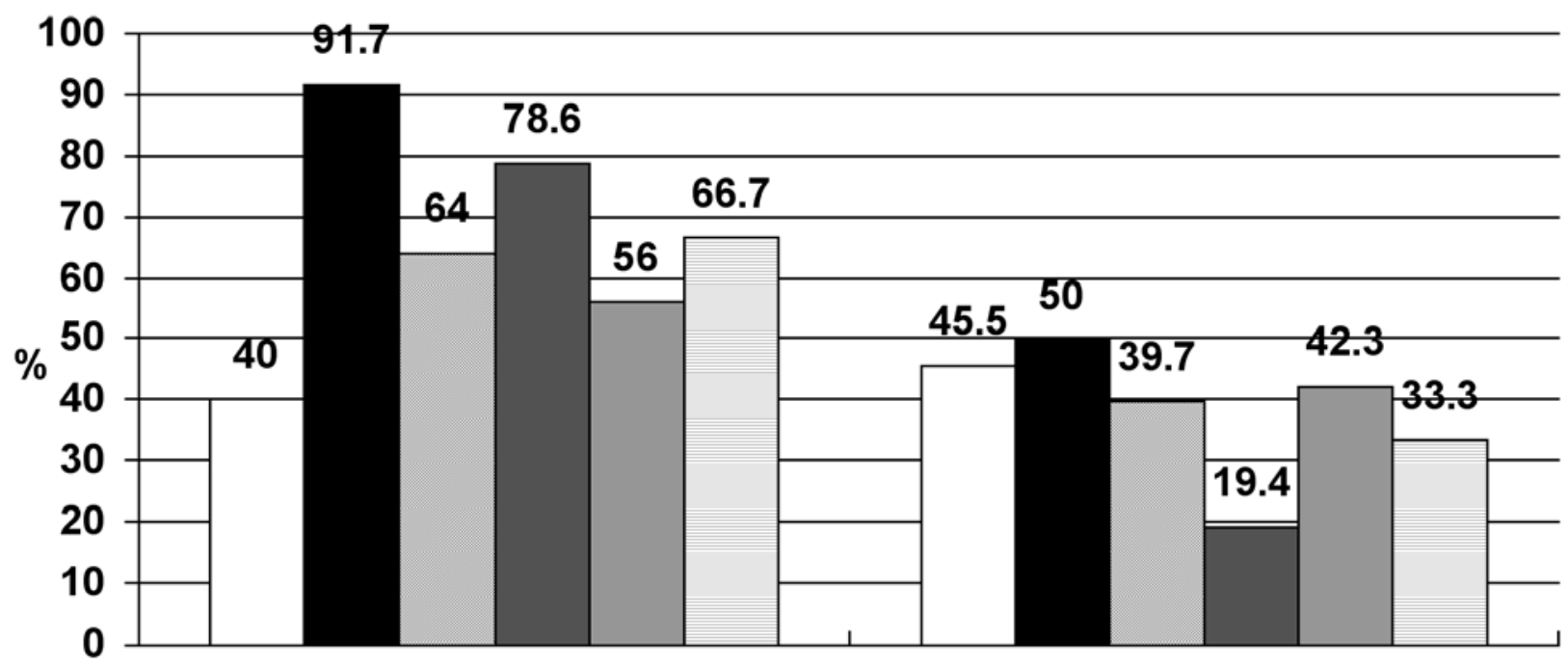

Nursing Students

Medical Students

$\square$ Knowledge Sterile Gloves

- Practice Sterile Gloves

- Knowledge non-Sterile Gloves

$\square$ Practice non-Sterile Gloves

Knowledge: Handling and disposal of needleticks and other sharp objects

- Practice: Handling and disposal of needlesticks and other sharp objects

Figure 1. Knowledge and practice of the use of sterile and non-sterile gloves and of the handling and disposal of needlesticks and other sharp objects among nursing $(n=25)$ and medical $(n=78)$ students in a teaching hospital. 
When comparing knowledge among nursing students with regards to the use of non-sterile gloves, was verified that the compliance surpassed knowledge (Fisher Exact Test; $p=0.477)$. The inverse happened with the medical students $\left(\chi^{2}=3.254 ; p=0.071\right)$. However, no statistical difference was noted between the knowledge and the practice (Figure 1).

\section{Handling and disposal of needlesticks and other sharp objects}

While conducting a comparative evaluation of the level of knowledge and practice in handling and disposal of needlesticks and other sharp objects among nursing students, it was possible to see that their level of knowledge is lower (56.0\%) than the observed practice $(66.7 \%)$, although no statistical difference was noted (Fisher Exact Test; $p=1.000$ ) (Figure 1).

When comparing knowledge and practice among medical students regarding handling and disposal of needlesticks and other sharp objects, the authors verified that the level of knowledge $(42.3 \%)$ was higher than their compliance rate (33.3\%). However, no statistical difference was noted (Fisher Exact Test; $p$ $=1.000$ ).

\section{Discussion}

The knowledge that nursing and medical students exhibited about $\mathrm{HH}$ was higher than the level of practice; $p \leq 0.001$. When evaluating compliance percentage of nursing (26.9\%) and medical (2.6\%) students it was possible to verify greater compliance among nursing students, regarding the practice of hand hygiene. The data found called the authors' attention to those nursing (46.2\%) and medical (83.3\%) students that did not wash their hands neither before nor after any procedures, although in $75.0 \%$ of these instances, the necessary materials (water and soap) were available and ready to be used. ${ }^{6}$ Also, the authors highlighted the adherence on hand hygiene only after patient care, so much for nursing as for medical students, showing they are more concerned with their own protection than that of patients (Table I). Similar dates were found in another study with nursing staff. ${ }^{7}$

The results showed that, in spite of the fact that the students knew that they had to wash their hands before and after caring for a patient, their practice leaves a lot to be desired, especially with regards to the medical students. This is probably a reflection of the existing dichotomy between the theory and the practice that is seen in the teaching-learning process being adopted currently. ${ }^{8,9}$

Our data corroborate those found in other studies, ${ }^{8,10}$ which goes to show that education and knowledge, although fundamental, are not sufficient to foster a behavioral change regarding hand hygiene.

Physicians have been singled out as health science professionals who exhibit the least compliance regarding hand hygiene, ${ }^{8,11}$ while nurses exhibit the greatest compliance, ${ }^{12}$ and these data coincide with our findings. Maybe the adherence to hand hygiene went larger if there were access readiness and easiness for the alcohol gel. ${ }^{13}$ As observed in study where the introduction of the alcohol gel for the hygienic friction of the hands increased the nurses' compliance. $^{7}$ However, the modification of the behavior and the sustainability of the adherence to hand hygiene also depend of the integration of other components. ${ }^{11}$

Other papers have also shown this low compliance or lack thereof is directly related to the fact that professors and other healthcare professionals have not set and example, thereby acting as negative role models. ${ }^{8,10,14,15}$ The behavior exhibited by these models is observed, imitated and repeated by students and young professionals.

Two studies, one evaluating medical students, residents and attending physicians ${ }^{16}$ and the other ${ }^{17}$ evaluating second to fourth year nursing students showed that compliance with standard precautions was inversely proportional to years of experience and academic life, and was observed in both professions.

These results reinforce the importance of an educational foundation in the first years of undergraduate work, and must be followed throughout the students' academic life, to ensure that the professional does not enter the job market unprepared with respect to standard precaution measures. This academic preparation process must continue through permanent education programs. 
The practice of wearing sterile or non-sterile gloves among nursing students was higher, relative to the knowledge verified. Therefore, it was possible to determine that knowledge regarding indication for sterile gloves was weak (40.0\%).

Among medical students, knowledge and practice on the use of gloves was insufficient, and no statistically significant difference was observed. The authors verified that their level of knowledge on non-sterile gloves usage is low (39.7\%) and practice is even more incipient (19.4\%). These students performed better in terms of knowledge $(45.5 \%)$ and practice $(50.0 \%)$ regarding the use of sterile gloves. They are, however, insufficient for a safe practice. Similar results were found in another study, where $35 \%$ of the medical students didn't know the correct use of gloves. ${ }^{18}$

Results found on knowledge and practice of the use of gloves, allow the authors to state that nursing students performed better than medical students, even though percentage evaluation points to the fact that medical students have a greater body of knowledge on sterile glove usage.

A study performed with medical and nursing students yielded different data, and the practice of wearing gloves was significantly higher among medical students, relative to nursing students. ${ }^{19}$ In other study, in which only medical students were evaluated, it was possible to see that the use of glove scored the highest among the other precautions studied. ${ }^{20}$ Other authors showed that the gloves are the individual protection equipments of larger adherence on the part of the professionals. Although as much the knowledge as the compliance are frequently lowest to those wanted. ${ }^{21}$

Nursing students were more proficient in handling and disposing needlesticks and other sharp objects $(66.7 \%)$, relative to their knowledge on the matter (56.0\%). Conversely, the knowledge (42.3\%) exhibited by medical students surpassed their compliance (33.3\%). However, knowledge and compliance with this important protective measure are still incipient among the students enrolled for this study.

Among the standard precaution measures, many more studies on compliance with these measures by nursing and medical students have been found in the international literature, ${ }^{16,22,23}$ regarding the handling and/or disposal of needlesticks and other sharp objects, with a focus on biosafety. The authors found that five such studies were performed in Brazil: four of them with nursing students ${ }^{24-27}$ and one with medical students. ${ }^{28}$ Several studies have reported insufficient knowledge and low compliance with these standard precaution measures by the students. ${ }^{20,22,23,26,29,30}$

The results of this study agreed with the results of a Korean study which evaluated the knowledge and compliance of nursing and medical students with standard precautions. ${ }^{19}$ Although data on practice or compliance was based on reports, the results of this survey have shown that, globally speaking, nursing students exhibited more knowledge and were more compliant with the practices when compared to the results obtained with medical students.

Many studies have investigated the reasons preventing healthcare providers to comply with standard precaution measures. ${ }^{11,12}$ In addition to the negative influence on the part of the professional serving as role models, some authors highlight that the origin of the low compliance, especially regarding hand hygiene, lies in the academic training, ${ }^{8,10,14,15}$ while others point to individual, group and institutional factors. ${ }^{10,11}$ Also highlighted are cognitive factors, such as a possible explanation for the differences found among several healthcare providers regarding compliance with standard precautions, even in view of similar working conditions. ${ }^{14}$

There are many motives for the observed behavior. However, one can consider that the starting points are academic preparation and teaching strategies adopted. Promoting compliance with standard precaution measures implies behavioral changes. The dynamics of this change is complex and multifaceted, and involves many factors such as education, motivation and a reorganization of the context of the working environment. ${ }^{8}$ In view of this complexity, surveys reinforce the importance of permanent education $^{12,31}$ and point to the implementation of educational strategies, with multiple interventions, as the most effective and long-lasting means to foster compliance with standard precaution measures. ${ }^{32}$ The 
implementation of these interventions, with an aim to increase compliance, should take into consideration cultural differences and social needs, in addition to education and active participation on the part of the patient.

Therefore, it is possible to conclude that both groups of students are knowledgeable on hand hygiene, but that this knowledge is insufficient to make them comply with this measure, bringing to light a dichotomy between teaching and practice. With the exception of compliance with the use of sterile gloves on the part of the nursing students, the other standard precaution measures that were evaluated, both as regards to the theory and practice, were insufficient to ensure safe practice, thereby showing failures in the teachinglearning process, especially among medical students. In this study, the number of subjects was limited because of the methodological precision adopted for the evaluation criteria of knowledge and compliance with standard precaution measures being evaluated.

\section{Acknowledgements}

The authors wish to thank the research team for collaborating with data collection.

\section{References}

1. Garner JS. Guideline for isolation precautions in hospitals. Hospital Infection Control Pratices Advisory Commitee. Infect Control Hosp Epidemiol 1996; 17: 53-80.

2. Siegel JD, Rhinehart E, Jackson M, Chiarello L, and the Healthcare Infection Control Practices Advisory Committee, 2007 Guideline for isolation precautions: Preventing transmission of infectious agents in healthcare settings, June 2007. Public Health Service, US Department of Health and Human Services, Centers for Disease Control and Prevention, Atlanta, Georgia. http://www.cdc.gov/ncidod/ dhqp/pdf/guidelines/Isolation2007.pdf [Accessed December 12, 2007]

3. Naikoba S, Hayward A. The effectiveness of interventions aimed at increasing handwashing in healthcare workers - a systematic review. J Hosp Infect 2001; 47: 173-180.

4. Gould DJ, Hewitt-Taylor J, Drey NS, Gammon J, Chudleigh J, Weinberg JR. The Clean Your Hands Campaign: critiquing policy and evidence base. J Hosp Infect 2007; 65: 95-101.

5. Tipple AFV, Pereira MS, Hayashida M, Moriya TM, Souza ACS. O ensino do controle de infecção: um ensaio teóricoprático. Rev Latino-am Enferm 2003; 11: 245-250.

6. García-Zapata MRC. Precauções padrão: conhecimento e prática de acadêmicos de enfermagem e medicina para prevenção e controle de infecção em um hospital escola [MSc Dissertation] Goiânia: Faculdade de Enfermagem/ Universidade Federal de Goiás, 2008; 163 p.
7. Chittaro $M$, Calligaris L, Farneti $F$, Faruzzo A, Panariti M, Brusaferro S. Healthcare Workers' Compliance with Hand Hygiene After the Introduction of an Alcohol-Based Handrub. Int J Infect Contr 2009; http://www.ijic.info/article/ view/2490/2799 [Accessed May 30, 2009]

8. Akyol A, Ulusoy $\mathrm{H}$, Ozen I. Handwashing: a simple, economical and effective method for preventing nosocomial infections in intensive care units. J Hosp Infect 2006; 62: 395405.

9. Tipple AFV, Mendonça KM, Melo MC, Souza ACS, Pereira MS, Santos SLV. Higienização das mãos: o ensino e a prática entre graduandos na área de saúde. Acta Sci Health Sci 2007; 29: 107-114.

10. Souza ACS, Tipple AFV, Pereira MS, Prado MA. Desafios para o controle de infecções nas instituições de saúde: percepção dos enfermeiros. Cienc enferm 2002; 8: 19-30.

11. Pittet $D$, Hugonnet $S$, Harbarth $S$, et al. Effectiveness of a hospital-wide programme to improve compliance with hand hygiene. Infection Control Programme. Lancet 2000; 356: 1307-1312.

12. Pittet $D$. The Lowbury lecture: behaviour in infection control. J Hosp Infect 2004; 58: 1-13.

13. Pittet D. Hand hygiene promotion: 5 moments, 5 components, 5 steps, and 5 May 2009. Int J Infect Contr 2009; http://www. ijic.info/article/view/3519/2875 [Accessed May 29, 2009]

14. Pittet D, Simon A, Hugonnet $S$, Pessoa-Silva CL, Sauvan V, Perneger TV. Hand hygiene among physicians: performance, beliefs, and perceptions. Ann Intern Med 2004; 141: 1-8.

15. Hunt DC, Mohammudally A, Stone SP, Dacre J. Hand-hygiene behaviour, attitudes and beliefs in first year clinical medical students. I Hosp Infect 2005; 59: 371-373.

16. Helfgott AW, Taylor-Burton J, Garcini FJ, Eriksen NL, Grimes R. Compliance with universal precautions: knowledge and behavior of residents and students in a department of obstetrics and gynecology. Infect Dis Obstet Gynecol 1998; 6: 123-128.

17. Felix CCP. Avaliação da técnica de lavagem das mãos executada por alunos do curso de graduação em enfermagem [MSc Dissertation] São Paulo: Escola de Enfermagem/ Universidade de São Paulo, 2007; 138 p.

18. Mann CM, Wood A. How much do medical students know about infection control? J Hosp Infect 2006; 64: 366-370.

19. Kim KM, Kim MA, Chung YS, Kim NC. Knowledge and performance of the universal precautions by nursing and medical students in Korea. Am J Infect Control 2001; 29: 295-300.

20. Askarian M, Honarvar B, Tabatabaee HR, Assadian O. Knowledge, practice and attitude towards standard isolation precautions in Iranian medical students. J Hosp Infect 2004; 58: 292-296.

21. Hinkin J, Gammon J, Cutter J. Review of personal protection equipment used in practice. Br J Community Nurs 2008; 13: 14-19.

22. Elliott SK, Keeton A, Holt A. Medical students' knowledge of sharps injuries. J Hosp Infect 2005; 60: 374-377.

23. Yang $\mathrm{YH}$, Liou $\mathrm{SH}$, Chen $\mathrm{C}$, et al. The effectiveness of a training program on reducing needlestick injuries/sharp object injuries among soon graduate vocational nursing school students in southern Taiwan. J Occup Health 2007; 49: 424-429.

24. Andrade ADC, Sanna MC. Ensino de biossegurança na graduação de enfermagem: uma revisão da literatura. Rev Bras Enferm 2007; 60: 569-572. 
25. Souza ACS, Silva CF, Tipple AFV, Santos SLV, Neves HCC. O uso de equipamentos de proteção individual entre graduandos de cursos da área da saúde e a contribuição das instituições formadoras. Cienc Cuid Saude 2008; 7: 027-036.

26. Reis RK, Gir E, Canini SR. Accidents with biological material among undergraduate nursing students in a public Brazilian university. Braz / Infect Dis 2004; 8: 18-24.

27. Ximenes Neto FRG, Lira PF, Aragão AEA, Ponte MAC, Monteiro MAA. Biossegurança na assistência ao parto: uma análise dos saberes dos acadêmicos de enfermagem. Enfermería Global 2007; 11: 1-11.

28. Toledo Júnior AC, Ribeiro FA, Ferreira FG, Ferraz RM, Greco DB. Knowledge, attitudes, and practice regarding occupational risk of exposure to HIV among medical students at the Medical School of the Federal University of Minas Gerais. Rev Soc Bras Med Trop 1999; 32: 509-15.
29. Arteaga L, Balzano C, Carvajal A. Medical students' knowledge and attitudes towards standard precautions. I Hosp Infect 2007; 65: 371-383.

30. Souza ACS, Neves HCC, Tipple AFV, Santos SLV, Silva CF, Barreto RAS. Conhecimento dos graduandos de enfermagem sobre equipamentos de proteção individual: a contribuição das instituições formadoras. Rev Eletr Enf 2008; http://www. fen.ufg.br/revista/v10/n2/v10n2a14.htm [Accessed Nov 29, 2008]

31. Rosenthal E, Pradier C, Keita-Perse O, Altare J, Dellamonica $\mathrm{P}$, Cassuto JP. Needlestick injuries among French medical students. JAMA 1999; 281: 1660.

32. Aboelela SW, Stone PW, Larson EL. Effectiveness of bundle behavioural interventions to control healthcare-associated infections: a systematic review of the literature. J Hosp Infect 2007; 66: 101-108. 